\title{
Is the place of birth related to the mother's satisfaction with childbirth? A cross- sectional study in a rural district of the Lao People's Democratic Republic (Lao PDR)
}

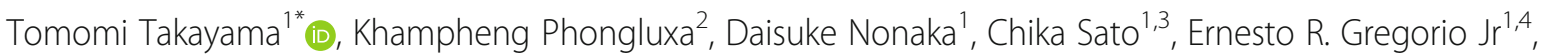
Nouhak Inthavong ${ }^{2}$, Tiengkham Pongvongsa ${ }^{5}$, Sengchanh Kounnavong ${ }^{2}$ and Jun Kobayashi ${ }^{1}$

\begin{abstract}
Background: The place of birth has been rapidly changing from home to health facility in Lao People's Democratic Republic (Lao PDR) following the strategy to improve the maternal and neonatal mortality. This change in the place of birth might affect the mother's satisfaction with childbirth. The objective of this study was to assess whether the place of birth is related to the mother's satisfaction with childbirth in a rural district of the Lao PDR.

Methods: A community-based survey was implemented in 21 randomly selected hamlets in Xepon district, Savannakhet province, between February and March, 2016. Questionnaire-based interviews were conducted with mothers who experienced a normal vaginal birth in the past 2 years. Satisfaction with childbirth was measured by the Satisfaction with Childbirth Experience Questionnaire. Using the median, the outcome variable was dichotomized into "high satisfaction group" and "low satisfaction group". Logistic regression was performed to assess the association between place of birth and satisfaction with childbirth. Three models were examined: In Model 1, only the predictor of interest (i.e., place of birth) was included. In Model 2, the predictor of interest and the obstetrical predictors were included. In Model 3, in addition to these predictors, socio-demographic and economic predictors were included. A mixed-effects model was used to account for the hierarchical structure.

Results: Among the 226 mothers who were included in data analysis, 60.2\% gave birth at the health facility and the remaining 39.8\% gave birth at home. Logistic regression analysis showed that the mothers who gave birth at the health facility were significantly more likely to have a higher level of satisfaction compared to the mothers who gave birth at home (crude odds ratio: 5.44, 95\% confidence interval: 3.03 to 9.75). This association remained even after adjusting for other predictors (adjusted odds ratio: 6.05, 95\% confidence interval: 2.81 to 13.03).

Conclusion: Facility-based birth was significantly associated with a higher level of satisfaction with childbirth among the mothers in the study district where maternal and neonatal mortalities are relatively high. The findings of the present study support the promotion of facility-based birth in a rural district of the Lao PDR.
\end{abstract}

Keywords: Childbirth satisfaction, Place of birth, Facility-based birth, Laos, Maternal health

\footnotetext{
* Correspondence: tomomi-t@umin.net

${ }^{1}$ Department of Global Health, Graduate School of Health Sciences,

University of the Ryukyus, 207 Uehara, Nishihara-cho, Nakagami-gun,

Okinawa, Japan

Full list of author information is available at the end of the article
}

(c) The Author(s). 2019 Open Access This article is distributed under the terms of the Creative Commons Attribution 4.0 International License (http://creativecommons.org/licenses/by/4.0/), which permits unrestricted use, distribution, and reproduction in any medium, provided you give appropriate credit to the original author(s) and the source, provide a link to the Creative Commons license, and indicate if changes were made. The Creative Commons Public Domain Dedication waiver (http://creativecommons.org/publicdomain/zero/1.0/) applies to the data made available in this article, unless otherwise stated. 


\section{Background}

Satisfaction with childbirth has a powerful effect on the mother's health and her baby's well-being. High satisfaction with childbirth can enhance the mother's relationship with their babies [1], and can empower personal strength and personal growth during the transition to motherhood $[2,3]$. In contrast, poor satisfaction with childbirth is known to be associated with poorer postnatal psychological adjustment [4], a higher rate of future abortions [5], preference for a future cesarean section $[6,7]$, and negative feelings towards the infant and breastfeeding [8]. Hence, improving mothers' satisfaction with childbirth is important for the well-being of mothers and their children.

Based on Subjective Well-being Theory, satisfaction with childbirth is conceptualized as a cognitive evaluation of whether the birth experience matches the mother's personal preferences $[9,10]$. Particularly, satisfaction is perceived with a "fit" between a mother's preferences and her birth environment [11]. A review summarized 54 studies in developing countries and identified the following determinants of mother's satisfaction with childbirth: 1) structure, such as childbirth environment; 2) process on how care was received, 3) outcome, such as child's health condition; and 4) physical condition, such as cost and access [12].

While home-based birth is still common among rural areas in developing countries [13-15], facility-based birth has gradually increased in recent years. According to the United Nations Children's Fund (UNICEF), the proportion of facility-based birth in the least developed countries has increased from $32 \%$ in 2009 to $54 \%$ in $2016[14,15]$. This change is based on the World Health Organization's (WHO) strategy [16] to prevent maternal death caused by delayed access to medical care [17]. Many developing countries are promoting facility-based birth following this strategy. For example, Lao People's Democratic Republic (Lao PDR), one of the least developed countries in Southeast Asia, has promoted facilitybased birth as a means of improving maternal and child health. Consequently, the proportion of facility-based birth in the country increased from 17\% in 2005 to $62.9 \%$ in 2017 [18].

The place of birth is an important component for childbirth because it is deeply related to the physical, emotional, cultural, and social aspects of childbirth [19]. Therefore, the shift in the place of birth in Lao PDR might affect the satisfaction with childbirth of mothers. Studies that examined the association between the place of birth and mothers' satisfaction with childbirth in the Netherlands and Canada showed that the mothers who gave birth at home were more satisfied than the mothers who gave birth at the hospital $[20,21]$. In these studies, feelings of control, amount of immediate contact with the baby, and non-medical home context were identified as the reasons behind the high satisfaction with childbirth at home. However, another study has reported that Syrian women prefer hospital birth, and the main reason for the preference is the feeling of being safe [22]. Moreover, another study which was conducted in Ethiopia described that mothers who had plans to birth at a health facility were positively associated with satisfaction with childbirth [23].

Previous studies conducted in Lao PDR investigated mother's satisfaction with delivery care and satisfaction with services provided to women who gave birth at a health facility $[24,25]$. These studies described that most of the mothers who gave birth at a health facility were generally satisfied, except with the accessibility to health facilities and cleanliness. Other Lao studies have qualitatively explored why Lao women choose to give birth at home. The reasons identified were convenience, low birth costs, comfort during childbirth, and traditional practices [26, 27].

Studies comparing the satisfaction with childbirth in terms of place of birth are rare, particularly in developing countries. Therefore, this study aims to assess whether the place of birth is related to the mother's satisfaction with childbirth in a rural district of the Lao PDR.

\section{Methods}

\section{Study site and participants}

We conducted a cross-sectional study in Xepon district, Savannakhet province. Xepon district is a rural district that is located along the Vietnamese border, approximately $500 \mathrm{~km}$ from the Vientiane capital. According to the Xepon district health office, $75 \%$ of the residents belong to ethnic minorities, such as Tri and Makong ethnic groups. The present study selected Xepon district as a poor and rural district of Lao PDR [28]. Moreover, the researchers have established a good working relationship with the local collaborators.

Xepon district has one district hospital and 14 health centers; all are public healthcare facilities. Xepon district includes 235 hamlets (a hamlet is a unit smaller than a village) according to the classification of the Xepon district health office. The district hospital covers 37 hamlets, and each health center covers between 6 and 43 hamlets.

The present study used a stratified cluster sampling to select the study participants. First, the public healthcare facilities in Xepon district were stratified into three strata: Stratum I, which is represented by the district hospital; Stratum II, which is consist of a total of five health centers located along the main road; and Stratum III, which is composed of a total of nine health centers that are not along the main road (Fig. 1). Second, we randomly selected three health centers from Stratum II 


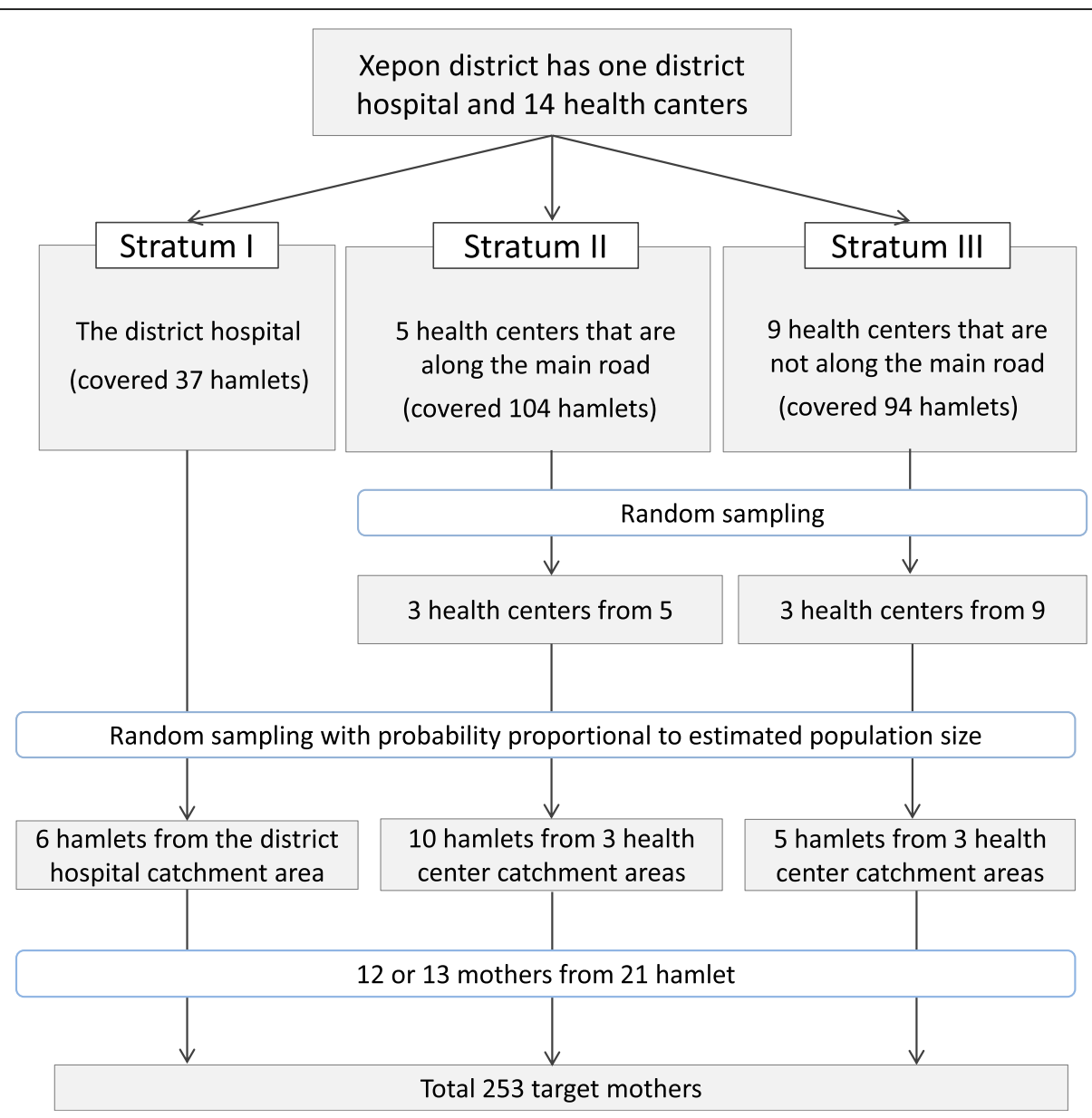

Fig. 1 Flowchart to select the the study participants

and III. Third, we also randomly selected six hamlets from Stratum I, ten hamlets from Stratum II, and five hamlets from Stratum III, with probability proportional to estimated population size. Finally, we included approximately 12 study participants from each of the selected 21 hamlets. The inclusion criteria are as follows: mothers who had a singleton and had a vaginal birth within the past 2 years. The exclusion criteria were mothers who experienced infant death during the most recent birth, had a history of mental disorders, or experienced a medical intervention (e.g., forceps delivery and vacuum extraction). Additionally, the mothers whose baby had serious complications, such as congenital diseases and cerebral palsy, were excluded because of the possible influence of such complications to mothers' satisfaction with childbirth.

In each hamlet, surveyors continued to recruit mothers until the target number of participating mothers (i.e., 12) had been reached. In one hamlet where the number of the eligible mothers who gathered did not reach the target number, the surveyors met the target number by inviting eligible mothers from a neighboring hamlet. Ultimately,
253 mothers participated in the study. We excluded six mothers based on the exclusion criteria (five mothers experienced mental disorder, and one mother experienced medical intervention). We excluded 18 mothers with missing information in the questionnaire. Three mothers who referred from home to hospital during birth were excluded because the transfer to facility during labour was likely to confound results relating to maternal satisfaction with childbirth [29]. This resulted in 226 mothers who were included in the data analysis.

\section{Data collection}

A public health research expert (KP) trained the surveyors on the ethical issues and data collection method for 2 days. The surveyors, who were health workers from the Xepon district health office and the Savannakhet provincial health office, collected data between February and March 2016. They conducted interviews with study participants in the selected hamlets, using a semi-structured questionnaire. A day prior to the scheduled visit to the selected hamlets, the surveyors requested eligible and willing mothers through the health volunteers of the 
hamlets to gather at a designated place of the hamlet to participate in the study. The surveyors then visited the hamlets and interviewed the mothers who were gathered. When the surveyors had difficulty in communicating with participating mothers in the Lao language, they asked the health volunteers of the hamlet to translate the Lao language into the ethnic language.

\section{Variables and measurement}

\section{Outcome variable}

The satisfaction with childbirth of mothers was measured using the seven question items obtained from the Satisfaction with Childbirth Experience Questionnaire (SWCh) [10]. SWCh is a theoretical measure based on subjective well-being theory. It was designed to assess global satisfaction with the childbirth experience and was confirmed to have content, criterion, and construct validity. High internal consistency (Cronbach's alpha $=$ 0.92) has been confirmed in an urban setting of the USA $[10,30]$. The original SWCh consists of seven items with seven-point Likert-type response options ranging from strongly disagree to strongly agree. For each positivelyphrased item, a score is obtained by giving one point for strongly disagree, and seven points for strongly agree. The code was reversed for item number 3 , which is a negatively-phrased statement. The total score ranges from 7 to 49, where higher scores indicate higher satisfaction.

To validate the SWCh for use in a rural Lao setting, a native Lao speaker who is engaged in public health research did the forward translation while a native English speaker who is an expert in maternal and child health and understands the Lao language, conducted the back translation. The research team compared the original and the back-translated English versions to ensure that semantic equivalence has been maintained and that words are appropriate for rural mothers. The questionnaire translated to ethnic language involving SWCh was not prepared for this study because the ethnic groups of the study participants do not have written language system [31]. The research team pre-tested the questionnaire with 20 mothers in two rural villages of the Lao
PDR. Based on the pre-test, the research team found that some respondents had difficulty understanding the Likert-type response style so that the research team developed a visual aid (additional file) and used it during the data collection to help with respondents' understanding. The present study collected data using SWCh's seven items. However, two items were excluded during the data analysis because inclusion of these two items resulted to the violation of the original single factor model and the Cronbach's alpha was reduced (i.e., 0.57).

As a result of excluding the two items, the present study used the following five items: (1) In most ways, my childbirth experience was close to my ideal; (2) The conditions of my childbirth experience were excellent; (3) If I could do it over, I would change some things about my childbirth experience; (4) I am satisfied with the experience of my baby's birth; (5) I got what I wanted out of my childbirth experience. The following two items were excluded during the analysis; My baby's birth did not go the way I wanted it to go; If I could do it over, I would change almost nothing about my childbirth experience. In the five-item scale, the total score ranged from 5 to 35. The factor loadings of each item were above 0.5 (Table 1), and the Cronbach's alpha was 0.75 .

\section{Predictor variables}

The predictor variable of interest was the place of birth for the most recent birth episode, which was measured by the question "Where did you give birth to your youngest child?". This question has six response options such as home, health center, district hospital, provincial hospital, forest and other.

Based on previous studies which examined the predictors of childbirth satisfaction [12, 32-34], the following predictor variables were also included in the present study; parity (primiparas/multiparas), labor length (less $6 \mathrm{~h} / 6 \mathrm{~h}$ to less than $24 \mathrm{~h} / 24 \mathrm{~h}$ or more), pregnancy complication (yes/ no), number of antenatal care received, age, educational attainment (no formal education/primary/secondary or above), ethnicity (Makong/Tri/Phouthay), possession of any vehicles (yes/no), decision maker of birth place (myself/husband/mother/mother-in-law/other), and household wealth.

Table 1 Descriptive statistics and maximum likelihood confirmatory factor analysis factor loadings for the satisfaction with childbirth items $(n=226)$

\begin{tabular}{|c|c|c|c|}
\hline Items & Mean & $\begin{array}{l}\text { Standard } \\
\text { deviation }\end{array}$ & $\begin{array}{l}\text { Factor I } \\
\text { loadings }\end{array}$ \\
\hline 1. In most ways, my childbirth experience was close to my ideal. & 5.8 & 1.7 & 0.66 \\
\hline 2. The conditions of my childbirth experience were excellent. & 6.0 & 1.5 & 0.78 \\
\hline $\begin{array}{l}3^{a} \text {. If I could do it over, I would change some things about my } \\
\text { childbirth experience. }\end{array}$ & 4.0 & 2.6 & 0.67 \\
\hline 4. I am satisfied with the experience of my baby's birth. & 6.1 & 1.5 & 0.77 \\
\hline 5. I got what I wanted out of my childbirth experience. & 5.8 & 1.5 & 0.77 \\
\hline
\end{tabular}

${ }^{\mathrm{a}}$ Reverse scored item 
To assess the household wealth, a household wealth index was built by principal component analysis [35]. The information used for the wealth index was the possession of household assets (bicycle, motorcycle, two-wheel-tractor with trailer/Tok Tok, radio, television, mobile phone, and cow) and house types (floor/wall/roof). By the wealth index, households were ranked and divided into quartiles.

\section{Statistical analysis}

Frequencies and medians with interquartile ranges were computed to summarize the data. The outcome variable was measured continuously. However, the present study did not use linear regression for multivariate analysis because the data did not meet the assumption for using linear regression: the residuals were not normally distributed. Therefore, the outcome variable was dichotomized into "high satisfaction group" (28 points or above) and "low satisfaction group" (fewer than 28 points), using the median (28 points) for logistic regression. Bivariate analyses were performed to assess the association between the outcome variable and each of the predictor variables using Fisher's exact test.

Multi-level modeling was used to account for the hierarchical structure of the data: mothers (at level 1) are nested within hamlets (at level 2), and the hamlets are nested within health center catchment areas (at level 3). Thus, a three-level, mixed-effects logistic regression model was used for the multivariate analysis. Three models were examined: In Model 1, only the predictor of interest (i.e., place of delivery) was included. In Model 2 , the predictor of interest and the obstetrical predictors were included. In Model 3, in addition to these predictors, socio-demographic and economic predictors were included. Stata 14.1 was used for performing the mixedeffects logistic regression analysis. Significance level was set at $<0.05$ for all tests.

Additional analysis was performed to confirm if the association between place of birth and satisfaction with childbirth would change after adding two items that had been excluded in the present study analysis.

\section{Results}

Socio-demographic and economic characteristics of study participants

Nearly three-quarters (73.0\%) were aged between 20 and 34 years old, with a median age of 25 year old (Table 2). The majority (69.5\%) belong to Makong/Tri ethnic group. Most of the participants (91.2\%) were farmers. More than half of the participants $(65.9 \%)$ did not receive a formal education. Approximately half of the participants (50.2\%) lived within $5 \mathrm{~km}$ of the health center, while $16.4 \%$ lived more than $9 \mathrm{~km}$ away. Almost three-fourths (73.8\%) possessed a vehicle, such as a motorcycle or Tok Tok (two-wheel-tractor with trailer).
Table 2 Socio-demographic and economic characteristics of the study participants $(n=226)$

\begin{tabular}{|c|c|c|}
\hline Characteristics & Number & Percent \\
\hline \multicolumn{3}{|l|}{ Age } \\
\hline$<20$ year & 31 & 13.7 \\
\hline 20 to 34 year & 165 & 73.0 \\
\hline$\geq 35$ year & 30 & 13.3 \\
\hline \multicolumn{3}{|l|}{ Ethnicity } \\
\hline Makong/Tri & 157 & 69.5 \\
\hline Phouthay & 69 & 30.5 \\
\hline \multicolumn{3}{|l|}{ Occupation } \\
\hline Farmer & 206 & 91.2 \\
\hline Other & 20 & 8.8 \\
\hline \multicolumn{3}{|l|}{ Husband's occupation } \\
\hline Famer & 194 & 85.8 \\
\hline Other & 32 & 14.2 \\
\hline \multicolumn{3}{|l|}{ Educational attainment } \\
\hline No formal education & 149 & 65.9 \\
\hline Primary ( 1 to 5 years) & 51 & 22.6 \\
\hline Secondary or above & 26 & 11.5 \\
\hline \multicolumn{3}{|c|}{ Distance from home to health facility ${ }^{a}$} \\
\hline$<5 \mathrm{~km}$ & 113 & 50.2 \\
\hline 5 to $9 \mathrm{~km}$ & 75 & 33.3 \\
\hline$>9 \mathrm{~km}$ & 37 & 16.4 \\
\hline \multicolumn{3}{|l|}{ Possession of any vehicles } \\
\hline Yes & 167 & 73.9 \\
\hline No & 59 & 26.1 \\
\hline
\end{tabular}

$\mathrm{a}_{n}=225$

\section{Obstetrical characteristics of study participants}

Regarding parity, three-fourths (77.4\%) of the participants were multiparas (Table 3). More than half (60.2\%) gave birth at a health facility, and the rest (39.8\%) gave birth at home. In the breakdown of the birth place of health facility, more than half (56.6\%) were gave birth at a health center, and the rest (43.4\%) were gave birth at the district hospital. All 136 participants who gave birth at a health facility were attended by a skilled birth attendant. Most of the participants who gave birth at home were attended by her family member including her husband, mother, or by a traditional birth attendant: eight mothers gave birth alone. Most of the participants (77.4\%) decided the place of birth by themselves. The most common self-reported health status during the pregnancy was "good" (73.9\%), followed by "bad" (26.1\%). The most commonly reported frequency of antenatal care visit for the pregnancy was "four times or more" (51.3\%), followed by "one to three times" (25.7\%) and "none" (23.0\%). Few participants (6.2\%) had pregnancy complications. 
Table 3 Obstetrical characteristics of the study participants $(n=226)$

\begin{tabular}{|c|c|c|}
\hline Characteristics & Number & Percent \\
\hline \multicolumn{3}{|l|}{ Parity } \\
\hline Primiparas & 51 & 22.6 \\
\hline Multiparas & 175 & 77.4 \\
\hline \multicolumn{3}{|l|}{ Experience of neonatal death } \\
\hline Yes & 42 & 18.6 \\
\hline No & 184 & 81.4 \\
\hline \multicolumn{3}{|l|}{ Place of birth } \\
\hline Health facility & 136 & 60.2 \\
\hline Home & 90 & 39.8 \\
\hline \multicolumn{3}{|l|}{ Attendant of birth } \\
\hline Skilled birth attendant & 136 & 60.2 \\
\hline Husband & 40 & 17.7 \\
\hline Mother & 26 & 11.5 \\
\hline No attendant & 8 & 3.5 \\
\hline Traditional birth attendant & 4 & 1.8 \\
\hline Other & 12 & 5.3 \\
\hline \multicolumn{3}{|l|}{ Length of Labor } \\
\hline$<6 h$ & 133 & 58.8 \\
\hline 6 to $24 \mathrm{~h}$ & 75 & 33.2 \\
\hline$>24 h$ & 18 & 8.0 \\
\hline \multicolumn{3}{|l|}{ Decision maker of birth place } \\
\hline Herself & 175 & 77.4 \\
\hline Husband & 24 & 10.6 \\
\hline Other & 27 & 11.9 \\
\hline \multicolumn{3}{|l|}{ Chronic illness } \\
\hline Yes & 21 & 9.3 \\
\hline No & 205 & 90.7 \\
\hline \multicolumn{3}{|l|}{$\begin{array}{l}\text { Self-reported health status } \\
\text { during pregnancy }\end{array}$} \\
\hline Good & 167 & 73.9 \\
\hline Bad & 59 & 26.1 \\
\hline \multicolumn{3}{|l|}{ Antenatal care visit } \\
\hline None & 52 & 23.0 \\
\hline 1 to 3 times & 58 & 25.7 \\
\hline$\geq 4$ times & 116 & 51.3 \\
\hline \multicolumn{3}{|l|}{ Pregnancy complication } \\
\hline Present & 14 & 6.2 \\
\hline Absent & 212 & 93.8 \\
\hline
\end{tabular}

Bivariate association between satisfaction with childbirth and socio-demographic and economic characteristics of study participants

No socio-demographic and economic characteristics were significantly associated with satisfaction with childbirth (Table 4).
Bivariate association between satisfaction with childbirth and obstetric characteristics of study participants

The participants who gave birth at a health facility were significantly more likely to have a higher level of satisfaction with childbirth (Table 5) compared to the participants who gave birth at home $(p<0.001)$. Being the decision maker of the birth place was significantly associated with satisfaction with childbirth $(p<0.001)$. Receiving antenatal care was significantly associated with satisfaction with childbirth $(p=0.035)$. The participants who did not have pregnancy complications were significantly more likely to have a higher level of satisfaction with childbirth compared to the participants who had pregnancy complications $(p=0.026)$.

\section{Multivariate analysis for the association between satisfaction with childbirth and place of birth}

Logistic regression analysis showed that mothers who gave birth at a health facility were significantly more likely to have a higher level of satisfaction compared to the mothers who gave birth at home (crude odds ratio: 5.44. 95\% confidence interval: 3.03 to 9.75) in Model 1 (Table 6). In Model 2, the association between the place of birth and satisfaction with childbirth remained statistically significant (adjusted odds ratio: 7.30, 95\% confidence interval: 3.51 to 15.16). In Model 3, the association remained statistically significant (adjusted odds ratio: $6.05,95 \%$ confidence interval: 2.81 to 13.03 ). Apart from the association with place of birth, pregnancy complication (adjusted odds ratio: 0.08, 95\% confidence interval: 0.02 to 0.42 ) and family member's decision on birth place (adjusted odds ratio: 3.80 , 95\% confidence interval: 1.62 to 8.92 ) were also significantly associated with childbirth satisfaction in Model 3.

The additional analysis using SWCh's seven original items also showed that mothers who gave birth at a health facility were significantly more likely to have higher level of satisfaction compared to the mothers who gave birth at home (adjusted odds ratio: 7.63, 95\% confidence interval: 3.25 to 17.91 in Model 3) (Table 7).

\section{Discussion}

The present study showed that mothers who gave birth at the health facility were significantly more likely to have a higher level of satisfaction with childbirth compared to mothers who gave birth at home in a rural district of Lao PDR. The association between the place of birth and satisfaction with childbirth can be considered robust because the strength of the association was strong (odds ratio: 5.44) [36] and remained largely unchanged (adjusted odds ratio: 6.05) even after adjusting for potential confounding factors.

One possible reason for the higher satisfaction among women who gave birth at a health facility is their exposure 
Table 4 Bivariate association between satisfaction with childbirth score and socio-demographic and economic characteristics of the study participants $(n=226)$

\begin{tabular}{|c|c|c|c|c|c|}
\hline \multirow[t]{2}{*}{ Characteristics } & \multicolumn{2}{|c|}{ Higher score group } & \multicolumn{2}{|c|}{ Lower score group } & \multirow{2}{*}{$\begin{array}{l}p \\
\text { value }^{\mathrm{a}}\end{array}$} \\
\hline & Number & Percent & Number & Percent & \\
\hline \multicolumn{6}{|l|}{$\overline{\text { Age }}$} \\
\hline$<20$ year & 14 & 45.2 & 17 & 54.8 & \multirow[t]{3}{*}{0.398} \\
\hline 20 to 34 year & 90 & 54.5 & 75 & 45.5 & \\
\hline$\geq 35$ year & 13 & 43.3 & 17 & 56.7 & \\
\hline \multicolumn{6}{|l|}{ Ethnicity } \\
\hline Makong/Tri & 41 & 59.4 & 28 & 40.6 & \multirow[t]{2}{*}{0.149} \\
\hline Phouthay & 76 & 48.4 & 81 & 51.6 & \\
\hline \multicolumn{6}{|l|}{ Religion } \\
\hline Buddhism & 41 & 59.4 & 28 & 40.6 & \multirow[t]{3}{*}{0.257} \\
\hline Animism & 74 & 49.0 & 77 & 51.0 & \\
\hline Other & 2 & 33.3 & 4 & 66.7 & \\
\hline \multicolumn{6}{|l|}{ Occupation } \\
\hline Farmer & 109 & 52.9 & 97 & 47.1 & \multirow[t]{2}{*}{0.350} \\
\hline Other & 8 & 40.0 & 12 & 60.0 & \\
\hline \multicolumn{6}{|l|}{ Husband's occupation } \\
\hline Farmer & 102 & 52.6 & 92 & 47.4 & \multirow[t]{2}{*}{0.572} \\
\hline Other & 15 & 46.9 & 17 & 53.1 & \\
\hline \multicolumn{6}{|l|}{ Educational attainment } \\
\hline No formal education & 73 & 49.0 & 77 & 51.0 & \multirow[t]{3}{*}{0.549} \\
\hline Primary (1 to 5 years) & 29 & 56.9 & 22 & 43.1 & \\
\hline Secondary or above & 15 & 57.7 & 11 & 42.3 & \\
\hline \multicolumn{6}{|c|}{$\begin{array}{l}\text { Distance from home to health } \\
\text { facility }^{\mathrm{b}}\end{array}$} \\
\hline$<5 \mathrm{~km}$ & 60 & 53.1 & 53 & 46.9 & \multirow[t]{3}{*}{0.881} \\
\hline 5 to $9 \mathrm{~km}$ & 37 & 49.3 & 38 & 50.7 & \\
\hline$>9 \mathrm{~km}$ & 19 & 51.4 & 18 & 48.6 & \\
\hline \multicolumn{6}{|l|}{ Possession of any vehicles } \\
\hline Yes & 92 & 55.1 & 75 & 44.9 & \multirow[t]{2}{*}{0.098} \\
\hline No & 25 & 42.4 & 34 & 57.6 & \\
\hline \multicolumn{6}{|l|}{ Household wealth quartile } \\
\hline First (poorest) & 34 & 59.6 & 23 & 40.4 & \multirow[t]{4}{*}{0.347} \\
\hline Second & 31 & 55.4 & 25 & 44.6 & \\
\hline Third & 26 & 47.3 & 29 & 52.7 & \\
\hline Fourth (least poorest) & 26 & 44.8 & 32 & 55.2 & \\
\hline
\end{tabular}

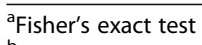

${ }^{b} n=225$

to delivery-related policy and programs, such as 'Free Maternal Health Service Policy' [37] and 'Skilled Birth Attendance Development Plan' [38], which are implemented at Lao health facilities. The 'Free Maternal Health Service Policy' was introduced by the Lao government in 2012 to promote the utilization of maternal health service and reducing financial burden. This policy covers all treatment, transportation support (2.5 to 6.5 USD) and a food fee during their stay in health facilities [37]. Because financial burden has been identified as a factor that influences mothers' satisfaction with childbirth [12], the implementation of this policy could have contributed to their satisfaction. Moreover, 'Skilled Birth Attendance Development Plan' might have also contributed to improved maternal 
Table 5 Bivariate association between satisfaction with childbirth score and obstetrical characteristics of the study participants $(n=226)$

\begin{tabular}{|c|c|c|c|c|c|}
\hline \multirow[t]{2}{*}{ Characteristics } & \multicolumn{2}{|c|}{ Higher score group } & \multicolumn{2}{|c|}{ Lower score group } & \multirow{2}{*}{$\begin{array}{l}p \\
\text { value }^{a}\end{array}$} \\
\hline & Number & Percent & Number & Percent & \\
\hline \multicolumn{6}{|l|}{ Parity } \\
\hline Primiparas & 24 & 47.1 & 27 & 52.9 & \multirow[t]{2}{*}{0.525} \\
\hline Multiparas & 93 & 53.1 & 82 & 46.9 & \\
\hline \multicolumn{6}{|c|}{ Experience of neonatal death } \\
\hline Yes & 21 & 50.0 & 21 & 50.0 & \multirow[t]{2}{*}{0.865} \\
\hline No & 96 & 52.2 & 88 & 47.8 & \\
\hline \multicolumn{6}{|l|}{ Place of birth } \\
\hline Health facility & 92 & 67.6 & 44 & 32.4 & \multirow[t]{2}{*}{$<0.001$} \\
\hline Home & 25 & 27.8 & 65 & 72.2 & \\
\hline \multicolumn{6}{|l|}{ Length of labor } \\
\hline$<6 h$ & 66 & 49.6 & 67 & 50.4 & \multirow[t]{3}{*}{0.770} \\
\hline 6 to $24 \mathrm{~h}$ & 41 & 54.7 & 34 & 45.3 & \\
\hline$>24 h$ & 10 & 55.6 & 8 & 44.4 & \\
\hline \multicolumn{6}{|c|}{ Decision maker of birth place } \\
\hline Herself & 78 & 44.6 & 97 & 55.4 & \multirow[t]{3}{*}{$<0.001$} \\
\hline Husband & 19 & 79.2 & 5 & 20.8 & \\
\hline Other & 20 & 74.1 & 7 & 25.9 & \\
\hline \multicolumn{6}{|l|}{ Chronic illness } \\
\hline Present & 8 & 38.1 & 13 & 61.9 & \multirow[t]{2}{*}{0.252} \\
\hline Absent & 109 & 53.2 & 96 & 46.8 & \\
\hline \multicolumn{6}{|c|}{$\begin{array}{l}\text { Self-reported health states } \\
\text { during pregnancy }\end{array}$} \\
\hline Good & 89 & 53.3 & 78 & 46.7 & \multirow[t]{2}{*}{0.453} \\
\hline Bad & 28 & 47.5 & 31 & 52.5 & \\
\hline \multicolumn{6}{|c|}{ Antenatal care visit } \\
\hline None & 20 & 38.5 & 32 & 61.5 & \multirow[t]{3}{*}{0.035} \\
\hline 1 to 3 times & 27 & 46.6 & 31 & 53.4 & \\
\hline$\geq 4$ times & 70 & 60.3 & 46 & 39.7 & \\
\hline \multicolumn{6}{|c|}{ Pregnancy complication } \\
\hline Present & 3 & 21.4 & 11 & 78.6 & \multirow[t]{2}{*}{0.026} \\
\hline Absent & 114 & 53.8 & 98 & 46.2 & \\
\hline
\end{tabular}

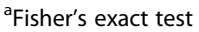

and child health service and eventual mothers' satisfaction [39]. This plan aims to ensure that adequate human resources are recruited, retained, supervised, and provided with the necessary skills and complemented by enabling environment (e.g., sphygmomanometer and fetoscope).

Our main finding concurs with several studies conducted in Lao PDR and other developing countries. Two studies conducted in Xiengkhuang province and Oudomxay province described that more than $80 \%$ of mothers who gave birth at the hospital were generally satisfied with the maternity health care, especially with the attitude of the medical staffs and medical service of the facilities [24, 25]. Other studies that focused on satisfaction with childbirth in Sri Lanka, Nepal, and Ethiopia also described that many mothers were satisfied with the health care services provided by a health facility, except for access, cost and waiting time in the hospital [40-43].

The low satisfaction of mothers who gave birth at home in the current study might have been influenced by the lack of assistance provided by skilled birth attendants. In the present study, no mothers who gave birth at home were attended by skilled birth attendants, and only $1.8 \%$ of them were supported by traditional birth attendants. Many of them were supported by a husband or family members. Skilled birth attendants give appropriate advice, guidance, and support during pregnancy, childbirth, and postnatal period [44]. Assistance from professionals could give a sense of security to mothers during labor. According to previous studies, the sense of security is described as one of the essential components of satisfaction with childbirth [30,45].

The main findings of the present study are not consistent with the primary findings of similar studies conducted in developed countries. Those studies described that mothers who gave birth at home were more satisfied than the mothers who gave birth at the hospital, and reported that less intervention and having close contact with the baby contributed to increasing the childbirth satisfaction [20, 21, 46, 47]. This difference might be attributed to the high quality of health services available in developed countries. Home-based delivery in a developed country is usually assisted by the skilled birth attendant, and if an abnormality occurs during birth, mothers can be immediately transferred to a medical facility under the care of experts.

In the present study, other factors that were positively related to satisfaction with childbirth were: 1) absence of pregnancy complication, and 2) family members' decisions on birth place. However, the present study could not identify the association because this study did not adjust for these confounding variables. To enhance the mother's satisfaction with childbirth in developing countries, future studies are recommended to explore the factors that are associated with the satisfaction with childbirth in consideration of high maternal and infant mortality and morbidity.

The utility rates of maternal healthcare services found in the present study were similar to those reported in the Lao Social Indicator Survey conducted between 2016 and 2017 [18]. For example, the proportion of facilitybased birth was $60.2 \%$ in the present study, whereas it was $60.5 \%$ in Savannakhet province. Similarly, the proportion of mothers who availed of antenatal care more than four times was $51.3 \%$ in the present study, whereas it was $53.4 \%$ in Savannakhet province. Therefore, the 
Table 6 Multivariate analysis for the place of birth and satisfaction with childbirth score after adjusting for confounding variables $(n=226)$

\begin{tabular}{|c|c|c|c|c|c|c|}
\hline & \multicolumn{2}{|c|}{ Model 1} & \multicolumn{2}{|c|}{ Model 2} & \multicolumn{2}{|c|}{ Model 3} \\
\hline & $\overline{\mathrm{OR}^{a}}$ & $95 \% \mathrm{Cl}^{\mathrm{b}}$ & $\overline{\mathrm{AOR}^{\mathrm{C}}}$ & $95 \% \mathrm{Cl}^{\mathrm{b}}$ & $\overline{\mathrm{AOR}^{\mathrm{C}}}$ & $95 \% \mathrm{Cl}^{\mathrm{b}}$ \\
\hline \multicolumn{7}{|l|}{ Place of birth } \\
\hline Home & 1.00 & Reference & 1.00 & Reference & 1.00 & Reference \\
\hline Health facility & 5.44 & 3.03 to 9.75 & 7.30 & 3.51 to 15.16 & 6.05 & 2.81 to 13.03 \\
\hline \multicolumn{7}{|l|}{ Parity } \\
\hline Primiparas & & & 1.00 & Reference & 1.00 & Reference \\
\hline Multiparas & & & 2.51 & 1.09 to 5.79 & 2.30 & 0.95 to 5.58 \\
\hline \multicolumn{7}{|l|}{ Labor length } \\
\hline$<6 h$ & & & 1.00 & Reference & 1.00 & Reference \\
\hline 6 to $24 \mathrm{~h}$ & & & 1.15 & 0.60 to 2.18 & 1.32 & 0.68 to 2.59 \\
\hline$>24 \mathrm{~h}$ & & & 0.94 & 0.31 to 2.83 & 0.75 & 0.23 to 2.48 \\
\hline \multicolumn{7}{|l|}{ Pregnancy complication } \\
\hline Absent & & & 1.00 & Reference & 1.00 & Reference \\
\hline Present & & & 0.15 & 0.37 to 0.65 & 0.08 & 0.02 to 0.42 \\
\hline \multicolumn{7}{|l|}{ Received antenatal care } \\
\hline None & & & 1.00 & Reference & 1.00 & Reference \\
\hline 1 to 3 times & & & 0.61 & 0.24 to 1.54 & 0.51 & 0.20 to 1.33 \\
\hline$\geq 4$ times & & & 1.03 & 0.44 to 2.40 & 1.04 & 0.41 to 2.63 \\
\hline \multicolumn{7}{|l|}{ Age } \\
\hline$<20$ year & & & & & 1.00 & Reference \\
\hline 20 to 34 year & & & & & 1.19 & 0.42 to 3.39 \\
\hline$\geq 35$ year & & & & & 0.94 & 0.24 to 3.77 \\
\hline \multicolumn{7}{|l|}{ Educational attainment } \\
\hline No formal education & & & & & 1.00 & Reference \\
\hline Primary school & & & & & 0.94 & 0.41 to 2.14 \\
\hline Secondary or above & & & & & 0.65 & 0.20 to 2.13 \\
\hline \multicolumn{7}{|l|}{ Ethnicity } \\
\hline Makong/Tri & & & & & 1.00 & Reference \\
\hline Phouthay & & & & & 0.81 & 0.34 to 1.92 \\
\hline \multicolumn{7}{|l|}{ Household wealth quartile } \\
\hline First (poorest) & & & & & 1.00 & Reference \\
\hline Second & & & & & 1.40 & 0.55 to 3.57 \\
\hline Third & & & & & 1.37 & 0.49 to 3.80 \\
\hline Fourth (least poor) & & & & & 1.07 & 0.38 to 3.01 \\
\hline \multicolumn{7}{|l|}{ Possession of any vehicles } \\
\hline Yes & & & & & 1.00 & Reference \\
\hline No & & & & & 0.88 & 0.41 to 1.91 \\
\hline \multicolumn{7}{|c|}{ Decision maker of birth place } \\
\hline Herself & & & & & 1.00 & Reference \\
\hline Other & & & & & 3.80 & 1.62 to 8.92 \\
\hline
\end{tabular}

${ }^{\mathrm{a}}$ Odds ratio. ${ }^{\mathrm{b}}$ Confidence Interval. ${ }^{\mathrm{C}}$ Adjusted odds ratio 
Table 7 Multivariate analysis for the place of birth and satisfaction with childbirth score after adjusting for confounding variables (SWCh 7item version) $(n=226)$

\begin{tabular}{|c|c|c|c|c|c|c|}
\hline & \multicolumn{2}{|c|}{ Model 1} & \multicolumn{2}{|c|}{ Model 2} & \multicolumn{2}{|c|}{ Model 3} \\
\hline & $\overline{\mathrm{OR}^{a}}$ & $95 \% \mathrm{Cl}^{\mathrm{b}}$ & $\overline{\mathrm{AOR}^{\mathrm{C}}}$ & $95 \% \mathrm{Cl}^{\mathrm{b}}$ & $\overline{\mathrm{AOR}^{\mathrm{C}}}$ & $95 \% \mathrm{Cl}^{\mathrm{b}}$ \\
\hline \multicolumn{7}{|l|}{ Place of birth } \\
\hline Home & 1.00 & Reference & 1.00 & Reference & 1.00 & Reference \\
\hline Health facility & 5.17 & 2.66 to 10.02 & 8.83 & 3.91 to 19.95 & 7.63 & 3.25 to 17.91 \\
\hline \multicolumn{7}{|l|}{ Parity } \\
\hline Primiparas & & & 1.00 & Reference & 1.00 & Reference \\
\hline Multiparas & & & 3.13 & 1.25 to 7.81 & 3.22 & 1.23 to 8.43 \\
\hline \multicolumn{7}{|l|}{ Labor length } \\
\hline$<6 h$ & & & 1.00 & Reference & 1.00 & Reference \\
\hline 6 to $24 \mathrm{~h}$ & & & 1.34 & 0.66 to 2.72 & 1.37 & 0.66 to 2.81 \\
\hline$>24 \mathrm{~h}$ & & & 0.39 & 0.12 to 1.27 & 0.36 & 0.11 to 1.21 \\
\hline \multicolumn{7}{|l|}{ Pregnancy complication } \\
\hline Absent & & & 1.00 & Reference & 1.00 & Reference \\
\hline Present & & & 0.24 & 0.06 to 0.97 & 0.23 & 0.05 to 1.03 \\
\hline \multicolumn{7}{|l|}{ Received antenatal care } \\
\hline None & & & 1.00 & Reference & 1.00 & Reference \\
\hline 1 to 3 times & & & 0.35 & 0.13 to 0.94 & 0.30 & 0.11 to 0.86 \\
\hline$\geq 4$ times & & & 0.58 & 0.23 to 1.50 & 0.47 & 0.17 to 1.31 \\
\hline \multicolumn{7}{|l|}{ Age } \\
\hline$<20$ year & & & & & 1.00 & Reference \\
\hline 20 to 34 year & & & & & 0.51 & 0.16 to 1.65 \\
\hline$\geq 35$ year & & & & & 0.41 & 0.09 to 1.85 \\
\hline \multicolumn{7}{|l|}{ Educational attainment } \\
\hline No formal education & & & & & 1.00 & Reference \\
\hline Primary school & & & & & 1.29 & 0.53 to 3.13 \\
\hline Secondary or above & & & & & 0.84 & 0.22 to 3.16 \\
\hline \multicolumn{7}{|l|}{ Ethnicity } \\
\hline Makong/Tri & & & & & 1.00 & Reference \\
\hline Phouthay & & & & & 0.68 & 0.24 to 1.90 \\
\hline \multicolumn{7}{|l|}{ Household wealth quartile } \\
\hline First (poorest) & & & & & 1.00 & Reference \\
\hline Second & & & & & 0.63 & 0.22 to 1.76 \\
\hline Third & & & & & 0.72 & 0.24 to 2.21 \\
\hline Fourth (least poor) & & & & & 0.83 & 0.26 to 2.62 \\
\hline \multicolumn{7}{|l|}{ Possession of any vehicles } \\
\hline Yes & & & & & 1.00 & Reference \\
\hline No & & & & & 0.78 & 0.33 to 1.88 \\
\hline \multicolumn{7}{|c|}{ Decision maker of birth place } \\
\hline Herself & & & & & 1.00 & Reference \\
\hline Other & & & & & 1.78 & 0.74 to 4.28 \\
\hline
\end{tabular}

adds ratio. ${ }^{\mathrm{b}}$ Confidence Interval. ${ }^{\mathrm{c}}$ Adjusted odds ratio 
findings of the present study might be apply to other rural districts in Savannakhet province.

To the best of our knowledge, the present study is the first to quantitatively study the association between place of delivery and satisfaction with childbirth in Lao PDR or any other Southeast Asian country. Previous studies in Lao PDR have explored the satisfaction with maternal care services in health facilities. This study is original in that it includes hypothesis-based analysis, including not only the mothers who gave birth at a health facility but also the mothers who gave birth at home. The Lao Government's strategy of promoting facility-based birth might have contributed to the mother's health and her baby's well-being, as well as safe birth. The results of this study support the strategy of promoting facility-based birth in Lao PDR.

Our study has some limitations. First, the study included mothers who arrived first in the meeting place of their hamlet. This group of mothers might have more interest in healthcare compared to mothers who arrived late. This possible selection bias might have contributed to higher satisfaction among mothers who gave birth at a health facility. Second, the present study used the fiveitem scale that has not been used in previous studies. The researcher had to eliminate the two items from the original, seven-item SWCh in order to keep the original single factor model and to increase the reliability of the Cronbach's alpha. However, the five-item scale used in the present study ensured construct validity; the main findings are unlikely to change even if the original seven-item scale had been used in the present study. Third, while the present study found significant association between the place of birth and satisfaction with childbirth, due to the cross-sectional nature of the study, this association does not necessarily mean causation. The fourth limitation is that the present study did not measure the satisfaction of maternal care. Therefore, the present study could not discuss the quality of maternal care provided by health facilities in Lao PDR. To promote facility-based birth and enhance the satisfaction with childbirth, future studies will be needed to evaluate the quality of maternal care and supply-side readiness of facility-based birth [37, 48, 49].

\section{Conclusion}

The facility-based birth was significantly associated with a higher level of satisfaction with childbirth among mothers in the study district where maternal and neonatal mortalities are relatively high. There is a possibility that women living in a rural district of Savannakhet province can improve their satisfaction with childbirth if they change the place of birth from home to a facility. The results of the present study support the strategy of promoting facility-based birth in Lao PDR.

\section{Abbreviations}

Lao PDR: Lao People's Democratic Republic; SWCh: Satisfaction with

Childbirth Experience Questionnaire; UNICEF: United Nations Children's Fund; WHO: World Health Organization

\section{Acknowledgments}

We would like to thank the study participants. We also thank the staff of the Xepon District Health Office, the Savannakhet Provincial Health Department, and Lao Tropical and Public Health Institute for their contributions to the study.

\section{Authors' contributions}

$\Pi T$ was the principal investigator and drafted the manuscript with the help of DN. TT, KP and TP supervised the field survey and contributed to the data collection. TT and DN contributed to developing the sampling strategy, analyzing data and revising the manuscript. EG contributed to the interpretation of the data and revising the manuscript. NI contributed to the acquisition of the data. CS contributed to gathering local information and acquisition of the data. SK and JK contributed to the conception of the study and interpretation of the data. All authors read and approved the final manuscript.

\section{Funding}

This work was partly supported by The Grant for National Center for Global Health and Medicine (25A-5). The funding source did not have any role in the design, collection, analysis or interpretation of the data and in the writing of the manuscript.

\section{Availability of data and materials}

The datasets used and/or analyzed in this study are available from the corresponding author on reasonable request.

\section{Ethics approval and consent to participate}

Ethical approval for this study was obtained from the Ethical Review Committee of University of the Ryukyus for Epidemiological Study (No.249, Aug/2014) and the National Ethics Committee for Health Research of Lao PDR (Clearance No. 041/2015). Before starting the survey, trained surveyors explained the details of the study to the participants, such as its purpose, the nature of voluntary participation, information that would be collected, and how the researchers would keep and manage the information. Written informed consent was obtained from each participant.

\section{Consent for publication}

Not applicable.

\section{Competing interests}

The authors declare that they have no competing interests.

\section{Author details}

${ }^{1}$ Department of Global Health, Graduate School of Health Sciences, University of the Ryukyus, 207 Uehara, Nishihara-cho, Nakagami-gun, Okinawa, Japan. ${ }^{2}$ Lao Tropical and Public Health Institute, Samsenthai Road, Ban Kaognot, Sisattanak District, Vientiane Capital, Lao People's Democratic Republic. ${ }^{3}$ Asia Health and Educational Fund, 2-17-1, Nakaochiai, Shinjuku-ku, Tokyo, Japan. ${ }^{4}$ Department of Health Promotion and Education, College of Public Health, University of the Philippines Manila/SEAMEO-TROPMED Regional Center for Public Health, Hospital Administration, Environmental and Occupational Health, 625 Pedro Gil Street, Ermita, Manila, Philippines. ${ }^{5}$ Savannakhet Provincial Health Department, Thahea village,

Kaysone-Phomvihan District, Savannakhet, Lao People's Democratic Republic.

Received: 9 April 2019 Accepted: 28 August 2019

Published online: 11 September 2019

\section{References}

1. Leap N, Sandall J, Buckland S, Huber U. Journey to confidence: women's experiences of pain in labour and relational continuity of care. J Midwifery Womens Health. 2010;55:234-42.

2. Semenic SE, Callister LC, Feldman P. Giving birth: the voices of orthodox Jewish women living in Canada. J Obstet Gynecol Neonatal Nurs. 2004;33:80-7. 
3. Nelson AM. Transition to motherhood. J Obstet Gynecol Neonatal Nurs. 2003; 32:465-77.

4. Simpson M, Catling C. Understanding psychological traumatic birth experiences: a literature review. Women Birth. 2016;29:203-7.

5. Gottvall K, Waldenström U. Does a traumatic birth experience have an impact on future reproduction? BJOG. 2002;109:254-60.

6. Ryding EL. Lukasse M, Kristjansdottir H, Steingrimsdottir T, Schei B; Bidens study group. Pregnant women's preference for cesarean section and subsequent mode of birth - a six-country cohort study. J Psychosom Obstet Gynaecol. 2016:37:75-83.

7. Pang MW, Leung TN, Lau TK, Hang Chung TK. Impact of first childbirth on changes in women's preference for mode of delivery: follow-up of a longitudinal observational study. Birth. 2008:35:121-8.

8. Beck CT, Watson S. Impact of birth trauma on breast-feeding: a tale of two pathways. Nurs Res. 2008;57:228-36.

9. Pavot W, Diener E. Review of the satisfaction with life scale. Psychol Assess. 1993:5:164-72

10. Stevens NR, Wallston KA, Hamilton NA. Perceived control and maternal satisfaction with childbirth: a measure development study. J Psychosom Obstet Gynaecol. 2012;33:15-24.

11. Reich JW, Zautra AJ, Manne S. How perceived control and congruent spouse support affect rheumatoid arthritis patients. J Soc Clin Psychol. 1993; 12:148-63.

12. Srivastava A, Avan Bl, Rajbangshi P, Bhattacharyya S. Determinants of women's satisfaction with maternal health care: a review of literature from developing countries. BMC Pregnancy Childbirth. 2015;15:97.

13. Montagu D, Yamey G, Visconti A, Yoong J. Where do poor women in developing countries give birth? A multi-country analysis of demographic and health survey data. PLoS One. 2011;28(6):e17155.

14. The State of the World Children. United Nations Children's Fund, New York. 2009 https://mww.unicef.org/sowc09/docs/SOWC09_Table_8.pdf. Accessed 15 July 2019

15. The State of the World Children. United Nations Children's Fund, New York. 2017. https://www.unicef.org/publications/files/SOWC_2017_ENG_WEB.pdf. Accessed 15 July 2019.

16. Campbell OM, Graham WJ. Strategies for reducing maternal mortality: getting on with what works. Lancet. 2006;368:1284-99.

17. Thaddeus S, Maine D. Too far to walk: maternal mortality in context. Soc Sci Med. 1994;38:1091-110.

18. Lao Statistics Bureau. Lao social Indicator survey II 2017, survey findings report. Vientiane: Lao Statistics Bureau and UNICEF; 2018. https://www. unicef.org/publications/files/UNICEF_SOWC_2016.pdf. Accessed 15 July 2019

19. Grigg C, Tracy SK, Daellenbach R, Kensington M, Schmied V. An exploration of influences on women's birthplace decision-making in New Zealand: a mixed methods prospective cohort within the evaluating maternity units study. BMC Pregnancy Childbirth. 2014;14:210.

20. Christiaens W, Bracke P. Place of birth and satisfaction with childbirth in Belgium and the Netherlands. Midwifery. 2009;25:11-9.

21. Fleming AS, Ruble DN, Anderson V, Flett GL. Place of childbirth influences feeling of satisfaction and control in first-time mothers. J Psychosom Obstet Gynecol. 1988:8:1-17.

22. Bashour H, Abdulsalam A. Syrian women's preferences for birth attendant and birth place. Birth. 2005;32:20-6.

23. Bitew K, Ayichiluhm M, Yimam K. Maternal satisfaction on delivery service and its associated factors among mothers who gave birth in public health facilities of Debre Markos town, Northwest Ethiopia. BioMed Res Int. 2015;2015:460767.

24. Phommchanh K, Yoshitoku Y, Mohammad BS, Chanthalangsy T, Joshua AR, Nobuyuki H. Delivery care satisfaction at government hospitals in Xiengkhuang Province under the maternal and child health strategy in Lao PDR. Nagoya J Med Sci. 2015;77:69-79.

25. Chankham T, Yamamoto E, Reyer JA, Arafat R, Khonemany I, Panome S, Hongkham D, Bounfeng P, Anonh X, Hamajima N. Knowledge of free delivery policy among women who delivered at health facilities in Oudomxay Province, Lao PDR. Nagoya J Med Sci. 2017;79:135-45.

26. Sychareun V, Hansana V, Somphet V, Xayavong S, Phengsavanh A, Popenoe R. Reasons rural Laotians choose home deliveries over delivery at health facilities: a qualitative study. BMC Pregnancy Childbirth. 2012;12:86.

27. Sanaphay A, Daenseekaew S, Smith JF, Eckermann E, Scopaz A. Home delivery in southern Lao PDR: challenges to achieving MDG $4 \& 5$ targets. Philipp J Nurs. 2014;1:24-31.

28. Coulombe $\mathrm{H}$, Epprecht M, Pimhidzai O, Sisoulath V. Where are the poor? Lao PDR 2015 census-based poverty map: province and district level results (English).
Washington, D.C: World Bank Group; 2016. http://documents.worldbank.org/ curated/en/477381468415961977/Where-are-the-poor-Lao-PDR-2015-censusbased-poverty-map-province-and-district-level-results. Accessed 15 July 2019

29. Christiaens W, Gouwy A, Bracke P. Does a referral from home to hospital affect satisfaction with childbirth? A cross-national comparison. BMC Health Serv Res. 2007:7:109

30. Nilvér H, Begley C, Berg M. Measuring women's childbirth experiences: a systematic review for identification and analysis of validated instruments. BMC Pregnancy Childbirth. 2017;17:203.

31. Ministry of Health. Ethnic group development plan. Vientiane: Department of Planning and Finance; 2011. http://www.google.co.jp/url?sa=t\&rct=i\&q= \&esrc $=$ \&\&source $=$ web\& $c d=3 \&$ ved $=2$ ahUKEwjYp_DgwrfkAhURvJQKHbKTD3 wQFjACegQIAxAC\&url=http\%3A\%2F\%2Fdocuments.worldbank.org\%2 Fcurated\%2Fen\%2F145071468265777291\%2FIPP4950P1249061 Budget0and0dislosure.doc\&usg=AOvVawOC

32. Hodnett ED. Pain and women's satisfaction with the experience of childbirth: a systematic review. Am J Obstet Gynecol. 2002;186(Suppl 5):160-72.

33. Bohren MA, Hunter EC, Munthe-Kaas HM, Souza JP, Vogel JP, Gülmezoglu AM. Facilitators and barriers to facility-based delivery in low- and middle-income countries: a qualitative evidence synthesis. Reprod Health. 2014;11:71.

34. Smarandache A, Kim TH, Bohr Y, Tamim H. Predictors of a negative labour and birth experience based on a national survey of Canadian women. BMC Pregnancy Childbirth. 2016;16:114.

35. Vyas S, Kumaranayale L. Constructing socio- economic status in indices: how to use principal components analysis. Health Policy Plan. 2006;21:459-68.

36. Cohen J. A power primer. Psychol Bull. 1992:112:155-9.

37. World Bank. Maternal health out-of-pocket expenditure and service readiness in Lao PDR: evidence for the national free maternal and child health policy from a household and health center survey. Washington DC The World Bank; 2013. p. 1-6. https://openknowledge.worldbank.org/ handle/10986/16742.

38. Ministry of health. Midwives in Lao PDR. Scaling up skilled birth attendance: putting midwives at the community-level towards achieving MDGs for mothers and children. 2012.

39. Alvesson HM, Lindelow M, Khanthaphat B, Laflamme L. Changes in pregnancy and childbirth practices in remote areas in Lao PDR within two generations of women: implications for maternity services. Reprod Health Matters. 2013;21:203-11.

40. Senarath U, Femando DN, Rodirgo I. Factors determining client satisfaction with hospital-based perinatal care in Sri Lanka. Tropical Med Int Health. 2006;11:1442-51.

41. Mehata S, Paudel YR, Dariang M, Aryal KK, Paudel S, Mehta R, King S, Barnet S. Factors determining satisfaction among facility-based maternity clients in Nepal. BMC Pregnancy Childbirth. 2017;17:319.

42. Mekonnen ME, Yalew WA, Anteneh ZA. Women's satisfaction with childbirth care in Felege Hiwot Referral Hospital, Bahir Dar city, Northwest Ethiopia. BMC Res Notes. 2015;8:528

43. Marama T, Bayu H, Merga M, Binu W. Patient satisfaction and associated factors among clients admitted to obstetrics and gynecology wards of public hospitals in Mekelle town, Ethiopia: An Institution-Based CrossSectional Study. Obstet Gynecol Int. 2018;2018:2475059.

44. World Health Organization. Making pregnancy safer: the critical role of the skilled attendant : a joint statement by WHO, ICM and FIGO. Geneva; 2004. https:/apps.who.int/iris/bitstream/handle/10665/42955/924? sequence=1. Accessed 15 July 2019

45. Ryding EL, Wijma K, Wijma B. Experiences of emergency cesarean section: a phenomenological study of 53 women. Birth. 1998;25:246-51.

46. Cunningham J. Experiences of Australian mothers who gave birth either at home, at a birth Centre, or in hospital labour wards. Soc Sci Med. 1993;36:475-83.

47. Ruth Z, Kelly A, Lisa KL. Planned home birth: benefits, risks, and opportunities. Int J Womens Health. 2015;7:361-77.

48. Manithip C, Edin K, Sihavong A, Wahlström R, Wessel H. Poor quality of antenatal care services-is lack of competence and support the reason? An observational and interview study in rural areas of Lao PDR. Midwifery. 2013;29:195-202.

49. Sigalla GN, Bakar RR, Manongi RN. Experiences of facility-based delivery services among women of reproductive age in Unguja Island, Zanzibar: A Qualitative Study. J Fam Med. 2018;5:1149.

\section{Publisher's Note}

Springer Nature remains neutral with regard to jurisdictional claims in published maps and institutional affiliations. 